\title{
ANALISIS TEKSTUAL GAYA BAHASA IKLAN HARBOLNAS VERSI SAKIT JIWA TOKO ONLINE BUKALAPAK.COM DI INTERNET
}

\author{
Wasono Adi \\ Fakultas Ilmu Sosial, Universitas Negeri Jakarta \\ Email: adwasono35@gmail.com
}

\begin{abstract}
This paper aims to reveal the meaning of the style of the National Online Shopping Day advertising language or abbreviated as HARBOLNAS in 2016 BukaLapak.com online version of the mental illness with, textual analysis techniques from the ad text using the study of textual and contextual cohesion. The approach utilizes the concept of language style that focuses on grammatical aspects, words or groups of words that become references, substitutions, and ellipsis. It is seen that, the advertisement uses aspects of grammatical aspects in terms of references, substitutions, and ellipsis in the text that it uses to listen to the attention of its readers or prospective consumers. The discourse of the ad language is intentionally used even if it is not in accordance with the rules of language, this is more due to the efforts of the advertiser to provide information briefly and with an impact that can immediately affect the reader. Based on the above conclusions, it is recommended in the production of advertising texts to take advantage of the practice of language that has aesthetic values to attract the interest of readers, the target audience of advertisements or prospective consumers.
\end{abstract}

Keywords: Advertisements, Language Style, Grammatical Aspects

\begin{abstract}
ABSTRAK
Makalah ini bertujuan untuk mengungkap makna gaya bahasa iklan Hari Belanja Online Nasional atau disingkat HARBOLNAS tahun 2016 toko online BukaLapak.com versi sakit jiwa dengan, teknik analisis tekstual dari teks iklan tersebut dengan memanfaatkan kajian kohesi tekstual dan kontekstual. Pendekatan memanfaatkan konsep gaya bahasa yang memfokuskan pada aspek-aspek gramatikal, kata-kata atau kelompok kata yang menjadi referensi, substitusi, dan ellipsis. Terlihat bahwa, iklan tersebut menggunakan aspek aspek gramatikal dalam hal
\end{abstract}

1|Communicology Vol 6 No.2 Des. 2018 
referensi, substitusi, dan ellipsis dalam teks yang digunakannya untuk mearik perhatian pembacanya atau calon konsumen. Wacana bahasa iklan tersebut sengaja digunakan walaupun tidak sesuai dengan kaidah bahasa, hal ini lebih karena upaya dari pihak pengiklan untuk memberikan informasi secara singkat dan dengan dampak yang segera dapat mempengaruhi pembaca. Berdasarkan simpulan di atas direkomendasikan dalam produksi naskah iklan agar memanfaatkan praktik berbahasa yang memiliki nilai-nilai estetis untuk menarik minat pembaca, khalayak sasaran iklan atau calon konsumen.

Kata Kunci: Iklan, Gaya Bahasa, Aspek Gramatikal

\section{PENDAHULUAN}

Iklan merupakan salah satu bentuk komunikasi massa, karena iklan pada dasarnya adalah kegiatan komunikasi yang ditujukan kepada khalayak orang banyak, atau sebagian orang dan bersifat heterogen dan sekaligus memiliki karakteristik konsumen yang spesifik. Iklan juga memiliki fungsi utama yakni menyampaikan informasi tentang produk kepada massa, dimana penyampaian informasinya bisa menggunakan elemen verbal maupun nonverbal. Selain dari sisi aspek kreatif periklanan dan bahasa, fungsi iklan juga memiliki gaya terutama dalam hal penyampaiannya.

Gaya iklan selama ini banyak mengalami perubahan, menurut Leiss, et.al ( 1986) dalam Noviani (2002: 1) isi dan gaya iklan pada abad ke-20 yaitu 1) pendekatan berorientasi produk, 2)simbol-simbol produk, 3) personalisasi, dan 4) segmentasi pasar. Fokus periklanan terletak pada identifikasi gaya hidup konsumen dan makna-makna tindakan konsumsi dalam situasi sosial.

Benyamin Franklin (yang juga dikenal sebagai bapak bangsa, pendiri negara Amerika Serikat) adalah orang pertama yang memperkaya informasi iklan dengan menambah ilustrasi sehingga efek iklan semakin kuat (Ferry Darmawan, 2005: 103-114). Selanjutnya, di Indonesia, pada masa perkembangan iklan sebagai alat komunikasi, bentuk iklan bersandar pada bahasa verbal yang tertulis dan tercetak. Kekuatan utama iklan terletak pada bahasa, gambar, serta penggarapan kreatif tata letaknya. Setiap pengiklan selalu menginginkan agar produk mereka yang dipromosikan melalui media iklan menjadi laku terjual. Sebab dampak langsung dan cepat 2|Communicology Vol 6 No.2 Des. 2018 
dari iklan terhadap penjualan menjadi salah satu ukuran keberhasilan iklan. Kunci kesuksesan sebuah iklan terletak pada kreativitas orang-orang yang terlibat dalam proses pembuatannya

Produk, yang dapat berupa barang fisik, jasa atau ide, ditampilkan dalam iklan sebagai konteks sosial sedangkan konsumsi, berupa keinginan dan kebutuhan terhadap produk tersebut, ditampilkan dalam makna gaya hidup. Dengan berbagai macam strategi periklanan yang salah satu caranya adalah dengan mengacu pada realita sosial ada disekitar khalayak. Penulis mengidentifikasi bahwa dari sekian banyak wacana yang dapat digunakan dalam iklan, salah satu wacana yang dapat digunakan oleh iklan yaitu dengan cara mendasarkan diri pada realitas sosial. Hal ini dimaksudkan untuk menarik minat konsumen agar tergerak dan terpengaruh untuk membeli produk yang diiklankan, sehingga, bisa dikatakan bahwa iklan selalu berusaha menerapkan berbagai strategi periklanan yang bisa dimengerti dan ditangkapdengan mudah, dan dirasakan atau dialami oleh khalayak sasaran dari iklan tersebut..

Iklan sebagai sebuah teks adalah sistem tanda yang berorganisir menurut kode-kode yang merefleksikan nilai-nilai tertentu, sikap, dan keyakinan tertentu. Setiap pesan dalam iklan memiliki dua tingkatan makna, yaitu makna yang dikemukakan secara eksplisit di permukaan dan makna yang dikemukakan secara implisit di balik permukaan tampilan iklan (Noviani, 2002: 79) dalam Sumarlam, Anik Kusrianti et.al. (2004: 11).

Iklan memiliki fungsi persuasif karena wacana yang digunakan berupaya membujuk dan meyakinkan khalayak. Keraf (1985:119) menyatakan bahwa wacana persuasi adalah bentuk wacana yang bertujuan untuk mengubah pikiran pembaca agar pembaca menerima dan melakukan sesuai kehendak pengiklan. Di samping itu pengiklan mengikat konsumen dengan produk dan janji-janji yang disertakan (Iriantara, 1993:134).

Adanya integrasi konektivitas antara internet dengan jejaring sosial (jejaring media sosial dalam teori realitas sosial siber) memudahkan konsumen untuk mengetahui produk toko online yang ada. Situs toko online dapat memengaruhi keputusan konsumen untuk membeli produk yang ditawarkan di toko online tersebut dengan melakukan promosi melalui iklan. Setiap iklan online bisa diakses oleh konsumen, sehingga mereka dapat melihat dan memilih sesuai dengan kebutuhan mereka dan berakhir dengan keputusan pembelian.

3|Communicology Vol 6 No.2 Des. 2018 
Pemanfaatan internet sebagai media periklanan tentunya dapat membantu meningkatkan keputusan pembelian yang dilakukan oleh konsumen. Semakin ketat persaingan bisnis online, maka penyedia toko online akan berusaha menarik perhatian calon konsumennya, dengan berbagai upaya promosi pemasaran, salah satu caranya adalah dengan menarik perhatian calon konsumen melalui iklan-iklan yang menarik perhatian dari aspek penggunaan bahasanya.

Salah satu toko online yang hadir di Indonesia adalah BukaLapak.com. BukaLapak.com merupakan online market place terkemuka di Indonesia. BukaLapak.com menyediakan sarana jual-beli dari konsumen ke konsumen. BukaLapak mempunyai strategi memunculkan iklan situs mereka ketika calon konsumen/ pembeli mencari barang/ produk melalui mencari mesin pencari dan memunculkan informasi yang relevan tersebut. Ketika konsumen membuka sebuah tautan dalam rangka mencari produk, akan muncul tautan iklan website BukaLapak.

\section{MASALAH}

Berdasarkan latar belakang tersebut, maka rumusan masalah dalam makalah ini adalah: Bagaimana penggunaan gaya bahasa iklan BukaLapak.com di Internet?

\section{TUJUAN}

Tujuan penulisan makalah ini adalah mendeskripsikan gaya bahasa iklan Harbolnas 2016 toko online BukaLapak.com di Internet.

\section{MANFAAT}

Manfaat yang diharapkan dari makalah simposium nasional ini adalah:

1. Secara akademis makalah ini diharapkan dapat melengkapi karya-karya ilmiah terdahulu yang terkait dengan teori mengenai gaya bahasa, dan wacana penulisan iklan dari bidang bahasa.

2. Secara praktis makalah ini diharapkan bisa menjadi acuan dalam penulisan kreatif naskah iklan khususnya terkait penggunaan gaya bahasa dalam naskah iklan. 


\section{METODE}

Makalah ini berdasarkan penelitian terdahulu yang dilakukan oleh penulis ketika meneliti iklan online tersebut. Metode penelitian yang digunakan penulis adalah menggunakan metode deskriptif dan analisis tekstual.

Menurut Sugiyono (2012:11) metode penelitian deskriptif adalah penelitian yang dilakukan untuk mengetahui nilai variabel mandiri, baik satu variabel atau lebih tanpa membuat perbandingan atau menghubungkan antara variabel satu dengan yang lain. Sedangkan, analisis tekstual oleh Frey, Botan, Fredman dan Kreps (1991) dalam Morris (2003 : 101) didefinisikan sebagai sebuah metode dimana para peneliti komunikasi ingin menggambarkan, menafsirkan, dan mengevaluasi karakteristik dari pesan yang terdokumentasi (recorded).

Secara umum, Morris (2003: 101) berpendapat bahwa ada dua tujuan dari analisis tekstual dalam praktik jurnalisme. Pertama, untuk mengkaji bahasa yang digunakan para sumber dalam topik atau isu tertentu. Kedua, untuk mengkaji bagaimana makna bergerak dari sumber kepada khalayak. Termasuk melihat teks dengan beberapa variabel yang mendahuluinya.

\section{PEMBAHASAN}

\section{Iklan}

Pada awalnya Iklan merupakan salah satu wujud ragam bahasa jurnalistik yaitu ragam bahasa yang digunakan oleh insan kreatif di dalam industry pers, dalam hal ini wartawan, awalnya iklan digunakan untuk mendukung penerbitan pers (Sumarlam, et.al., 2009:169). Iklan mengandung daya informatif persuasif yang secara konsensus harus memilih kata-kata yang dimengerti oleh khalayak pembaca. Selanjutnya, iklan, selain memiliki daya informatif persuasif, iklan juga mempunyai sifat khas yang menjadi karakteristiknya, yaitu singkat, lancar, padat, sederhana, netral, dan menarik.

Dari sisi penggunaan bahasa, bahasa iklan mempunyai bentuk komunikasi yang khas. Oleh sebab karakteristik yang dimiliki oleh iklan tersebut, maka dapat dijelaskan bahwa iklan merupakan suatu alat komunikasi yang digunakan untuk menarik perhatian calon konsumen dalam menawarkan produk suatu perusahaan dengan tampilan gambar dan kata-kata yang menarik yang termuat dalam media elektronik maupun media cetak.

5|Communicology Vol 6 No.2 Des. 2018 


\section{Struktur Iklan}

Berkenaan dengan struktur wacana, wacana iklan mempunyai tiga unsur pembentuk struktur wacana, yaitu (1) Butir utama (Headline), (2) Batang tubuh atau isi (Body), dan (3) penutup (Closing) yang dalam struktur wacana iklan tersebut dikaitkan dengan permasalahan tahap-tahap untuk mencapai tujuan. Iklan merupakan salah satu media komunikasi yang sangat efektif untuk digunakan sebagai alat penghubung antara produsen dan konsumen.

Produsen sering menggunakan iklan sebagai alat untuk menawarkan atau mempromosikan produk-produknya. Oleh karena itu, semua perusahaan yang menghasilkan produk baru, berlomba-lomba dalam memasang iklan sebagus-bagusnya untuk memperoleh keuntungan yang maksimal dari hasil penjualan produk-produknya.

\section{Gaya Bahasa Iklan}

Selanjutnya, Sumarlam berpendapat, bahwa dari segi bahasa, umumnya kita bisa melihat dua macam bentuk gaya bahasa, yaitu: 1) Iklan dengan gaya bahasa lisan dan 2) Iklan dengan gaya bahasa tulis. (2009: 179).

Iklan dengan gaya bahasa lisan sering dijumpai di media elektronik seperti televisi dan radio, yang disampaikan dalam bentuk kata-kata yang diucapkan oleh sumber pesan, singkat namun menarik, disertai dengan gambar bergerak yang menarik (untuk televisi), dan komposisi audio-nya berupa musik dan efek suara, sedangkan untuk media audio-radio misalnya, kata-kata lisan yang diucapkan oleh sumber pesan tersebut dapat dibayangkan oleh pendengar dan biasanya juga disertai efek suara maupun musik. Sehingga dapat dikatakan bahwa iklan dengan gaya bahasa lisan adalah iklan yang memuat tentang produk dengan tampilan audio visual yang menarik, yang isi pesannya disampaikan dengan gaya penuturan lisan oleh sumber pesan .

Sedangkan iklan dengan gaya bahasa tulis, biasanya iklan yang sering dijumpai di media cetak (majalah, tabloid, surat kabar). Iklan dengan gaya bahasa tulis, terkadang juga disertai dengan dukungan visual berupa gambar-gambar yang menarik, tetapi peyampaian isi pesannya disampaikan dengan gaya penulisan teks, hanya berupa kata-kata dan, atau gambar yang

6|Communicology Vol 6 No.2 Des. 2018 
menarik, tetapi isi pesannya tidak disampaikan oleh penutur atau sumber pesan, melainkan pembaca atau khalayak sasarannya sendiri yang harus membaca pesan tersebut.

\section{Tujuan Iklan}

Tujuan pertama dalam wacana iklan adalah menarik perhatian. Untuk itu, diperlukan pesan-pesan iklan yang menarik dan penting sehingga dapat menarik perhatian calon konsumen (Sumarlam, et.al., 2009 : 180). Lebih lanjut, menurut Sumarlam (2009:180) tujuan ini ada pada butir utama. Dalam hal ini, ada lima proposisi dalam menarik perhatian konsumen yaitu (1) proposisi yang menekankan keuntungan calon konsumen, (2) proposisi yang membangkitkan rasa ingin tahu pada para calon konsumen, (3) proposisi yang berupa pertanyaan yang menuntut perhatian lebih, (4) proposisi yang memberi komando atau perintah kepada calon konsumen, dan (5) proposisi yang menarik perhatian konsumen khusus.

Contoh kata-kata yang digunakan untuk tujuan menarik perhatian dan biasanya ditulis dalam huruf kapital dan tanda baca, misalnya:

\section{“BARU!”, “HARGA PROMO”, “CUCI GUDANG, HARGA DIBANTING!”, “AWAS KUMAN MENGINTAI!"}

Tujuan kedua, setelah menarik perhatian, berikutnya adalah membangkitkan kesadaran calon konsumen. Berdasarkan motif calon konsumen dalam membeli sesuatu, yaitu motif emosional dan motif rasional, diwadahi dalam bagian badan iklan. Wacana iklan hendaknya mengandung alasan objektif (rasional) dan alasan subjektif (emosional). Alasan objektif berupa informasi yang dapat diterima oleh nalar calon konsumen sedangkan alasan subjektif berupa halhal yang dapat mengajak emosi calon konsumen.

Contoh teks atau kata-kata untuk membangkitkan kesadaran konsumen, misalnya dengan menggunakan tesis:

$$
\text { "Apapun makanannya, minumnya Teh Botol Sosro." }
$$

Atau dapat berupa wacana seperti berikut ini, untuk memberikan alasan rasional yang kuat bagi pembaca iklan sebuah produk suplemen kesehatan:

7|Communicology Vol 6 No.2 Des. 2018 


\section{MASALAH-MASALAH YANG MUNCUL AKIBAT OBESITAS}

Berat badan yang berlebihan dalam dunia kesehatan dikenal sebagai obesitas (kegemukan). Obesitas dalam hal ini didefinisikan sebagai sebuah kondisi di mana tubuh manusia menyimpan lemak yang berlebih. Obesitas sangat potensial menyebabkan gangguan pada kesehatan manusia.

Dalam dunia kedokteran, obesitas dikenal sebagai faktor utama penyebab penyakit jantung. Akibat dari kelebihan berat badan, jantung bekerja lebih keras. Jika jantung bekerja terlalu keras, hal ini jelas sangat berbahaya bagi kesehatan. Serangan jantungpun dapat terjadi. Selain itu, obesitas dapat pula meningkatkan kolesterol serta tekanan darah. Tingginya kolestorol dan tekanan darah dapat menyebabkan pembuluh darah pecah sehingga apa yang disebut sebagai stroke, dapat terjadi. Tidak hanya masalah serangan jantung dan stroke, obesitas dapat pula meningkatkan jumlah gula dalam darah. Jumlah gula yang tidak terkontrol ini dapat menyebabkan gangguan kesehatan yang kita kenal sebagai diabetes.

Tujuan ketiga, dalam wacana iklan adalah mengubah tindakan tertentu pada diri konsumen dan tindakan tersebut diharapkan segera. Hal ini terdapat pada bagian penutup iklan. Dalam mengembangkan bagian penutup iklan, ada dua hal yang perlu dipertimbangkan yaitu pendekatan penjualan (seling approach) dan butir-butir pasif (passive point). Pendekatan penjualan yang dapat digunakan untuk mengakhiri bagian iklan adalah dengan cara keras (hard sell) atau dengan cara lemah (soft sell).

Contoh teks atau kata-kata untuk mengubah tindakan dengan segera:

"SEGERA, SEBELUM KEHABISAN!",

"JANGAN SAMPAI MENYESAL!",

"LAKUKAN SEBELUM TERLAMBAT!"

"Langganan, Yuk!"

\section{Analisis Teks}

Penulis dalam penelitiannya melakukan analisis teks pada beberapa iklan promosi Hari Belanja Online Nasional atau disingkat Harbolnas di toko online BukaLapak.com di Internet dari

$\mathbf{8} \mid$ Communicology Vol 6 No.2 Des. 2018 
aspek gaya bahasa dan menemukan beberapa aspek gramatikal yang dibahas dalam makalah ini, seperti yang terdapat dalam dua gambar berikut ini:

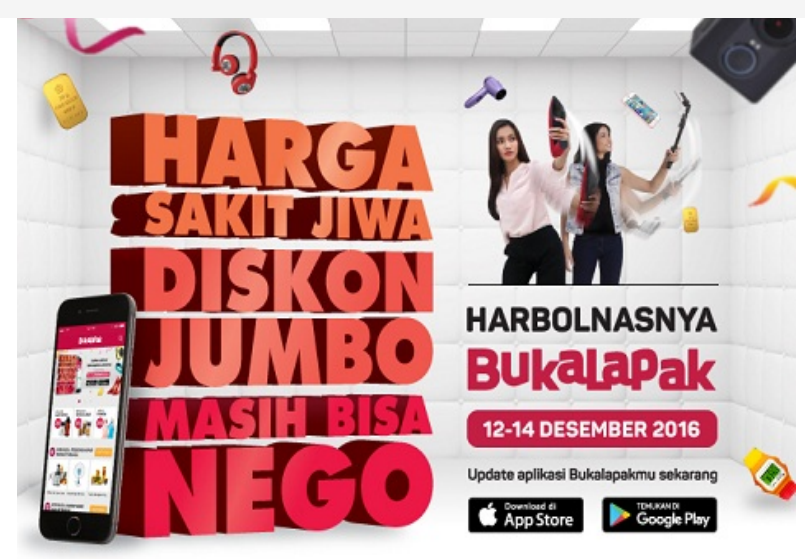

\section{Gambar 1}

Iklan Harbolnas BukaLapak Sakit Jiwa Versi 1

(Sumber: https://www.bukalapak.com/about)

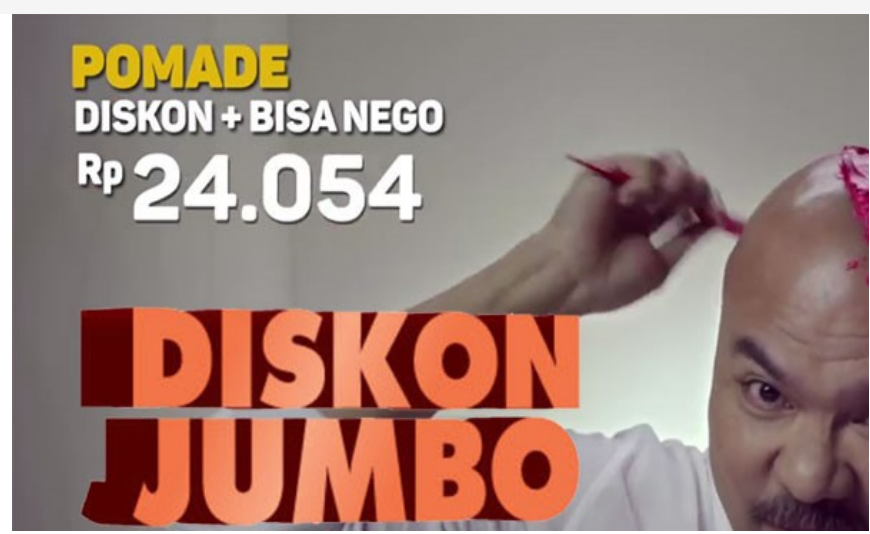

Gambar 2

Iklan Harbolnas BukaLapak Sakit Jiwa Versi 2

(Sumber: https://www.bukalapak.com/about)

Dari kedua gambar iklan diatas, maka ditemukan aspek gaya bahasa dan gramatikal, sebagai berikut:

9|Communicology Vol 6 No.2 Des. 2018 


\section{Kohesi}

Mulyana (2005: 26) menyatakan bahwa kohesi dalam wacana diartikan sebagai kepaduan bentuk yang secara struktural membentuk ikatan sintaktikal. Kohesi wacana terbagi di dalam dua aspek, yaitu kohesi gramatikal dan kohesi leksikal. Kohesi gramatikal antara lain adalah referensi, subtitusi, ellipsis, konjungsi, sedangkan yang termasuk kohesi leksikal adalah sinonimi, repetisi, kolokasi.

Sejalan dengan pendapat di atas Yayat Sudaryat (2008: 151) menyatakan bahwa kohesi merupakan aspek formal bahasa dalam organisasi sintaksis, wadah kalimat-kalimat disusun secara padu dan padat untuk menghasilkan tuturan. Sedangkan Abdul Rani, Bustanul Arifin, dan Martutik (2006: 88) menyatakan bahwa kohesi adalah hubungan antarbagian dalam teks yang ditandai oleh penggunaan unsur bahasa. Oleh karena itu, wacana dikatakan kohesif apabila terdapat kesesuaian bentuk bahasa baik dengan konteks atau situasi dalam bahasa, maupun konteks atau situasi diluar bahasa.

Dalam iklan Harbolnas versi Sakit Jiwa BukaLapak.com di Internet dapat dikatakan kohesif, karena terdapat kesesuaian bentuk bahasa dengan konteks didalam maupun diluar bahasa dari teks promosi: "Diskon Jumbo, Masih Bisa Nego".Karena antara kalimat "Diskon Jumbo" dengan kalimat "Masih Bisa Nego" dikatakan kohesif karena merupakan suatu tuturan.

\section{Hakikat Unsur Gramatikal} berikut:

Analisis terhadap iklan Harbolnas BukaLapak.com versi sakit jiwa adalah sebagai

\section{a. Referensi}

Menurut Yayat Sudaryat (2008:153) menyatakan bahwa referensi atau pengacuan merupakan hubungan antara kata dengan acuan. Kata-kata yang berfungsi sebagai pengacu disebut deiksis sedangkan unsur-unsur yang diacu disebut antesede.

Pendapat ini diperkuat dengan pendapat Mulyana (2005: 27) yang juga menyatakan bahwa referensi (penunjukan) merupakan bagian kohesi gramatikal yang berkaitan dengan penggunaan kata atau kelompok kata untuk menunjuk kata atau kelompok kata atau satuan gramatikal lainnya.

$\mathbf{1 0 | C o m m u n i c o l o g y ~ V o l ~} 6$ No.2 Des. 2018 
Dalam iklan Harbolnas versi sakit Jiwa tersebut, kata-kata atau kelompok kata yang diidentifikasi sebagai referensi ditunjukan pada kata: "DISKON" sebagai kata pengacu dan kata: “JUMBO” sebagai kata yang diacu.

\section{b. Subtitusi}

Harimurti Kridalaksana (dalam Mulyana, 2005:28) menyatakan bahwa subtitusi (penyulihan) adalah proses dan hasil penggantian oleh unsur bahasa oleh unsur lain dalam satuan yang lebih besar. Penggantian dilakukan untuk memperoleh unsur pembeda atau menjelaskan strukur tertentu. Proses subtitusi merupakan hubungan gramatikal, dan lebih bersifat hubungan kata dan makna.

Sejalan dengan pendapat tersebut Yayat Sudaryat (2008: 154) menyatakan bahwa subtitusi mengacu pada penggantian kata-kata dengan kata lain. Subtitusi mirip dengan referensi. Perbedaanya, referensi merupakan hubungan makna sedangkan subtitusi merupakan hubungan leksikal atau gramatikal.

Dalam iklan Harbolnas BukaLapak.com versi sakit jiwa, substitusi juga ditemukan pada penggunaan kata "DISKON" untuk menggantikan kata potongan harga, dan juga pada kata "JUMBO" untuk menggantikan makna kata "BESAR", serta terdapat pada kata "NEGO" untuk menggantikan kata "NEGOSIASI" atau kata "Ditawar" atau "tawar-menawar".

\section{c. Ellipsis}

Yayat Sudaryat (2008: 155) mengemukakan ellipsis merupakan penghilangan satu bagian dari unsur kalimat. Sebenarnya ellipsis sama dengan subtitusi, tetapi ellipsis disubtitusi oleh sesuatu yang kosong. Ellipsis biasanya dilakukan dengan menghilangkan unsur-unsur wacana yang telah disebutkan sebelumnya. Sedangkan pendapat Harimurti Kridalaksana (dalam Mulyana, 2005:28) berpendapat bahwa elipsis (penghilangan atau pelesapan) adalah proses penghilangan kata atau satuan-satuan kebahasaan lain.

Dalam iklan Harbolnas BukaLapak.com versi sakit jiwa, kata-kata "DISKON JUMBO MASIH BISA NEGO" telah mengalami suatu penghilangan atau ellipsis untuk memenuhi kaidah-kaidah dalam penulisan naskah kreatif iklan, walaupun tidak sesuai dari segi gramatikal 11|Communicology Vol 6 No.2 Des. 2018 
bahasa. Seharusnya kalimat tersebut ditulis lengkap seperti contoh ini: "DISKON JUMBO DAN MASIH BISA DINEGO”

\section{Paralelisme}

Menurut Yayat Sudaryat (2008: 155) paralelisme merupakan pemakaian unsur-unsur gramatikal yang sederajat. Hubungan antara unsur-unsur itu dituturkan langsung tanpa konjungsi. Seperti yang terlihat didalam contoh iklan tersebut dari rangkaian kalimat-kalimat yang menggunakan gaya penuturan langsung tanpa konjungsi atau kata sambung. Terdapat dalam kalimat:

\section{“HARGA SAKIT JIWA DISKON JUMBO MASIH BISA NEGO”}

\section{Konjungsi}

Harimurti Kridalaksana dan H. G. Tarigan dalam (Mulyana, 2005: 29) menyatakan bahwa konjungsi atau kata sambung adalah bentuk atau satuan kebahasaan yang berfungsi sebagai penyambung, perangkai, atau penghubung angtara kata dengan kata, frasa dengan frasa, kalusa dengan klausa, kalimat dengan kalimat dan seterusnya.

Dalam kasus iklan Harbolnas versi Sakit Jiwa BukaLapak.com, tidak ditemukan satu bentuk konjungsi atau kata sambung yang digunakan dalam kalimat "DISKON JUMBO MASIH BISA NEGO”. Hal ini karena penulisan kalimat tersebut lebih mementingkan kaidah-kaidah kreatif dalam penulisan naskah iklan dibandingkan untuk memenuhi kaidah-kaidah gramatikal bahasa.

\section{Analisis Konteks}

Cook (dalam Abdul Rani, et.al., 2006: 872) menyatakan bahwa penggunaan alat kohesi itu memang penting untuk membentuk wacana yang utuh, tetapi tidak cukup meggunakan penanda kata tersebut. Ada faktor lain seperti relevansi dan faktor tekstual luar (extratextual factor) yang ikut menentukan keutuhan wacana. Kesesuaian antara teks dan dunia nyata dapat membantu menciptakan suatu kondisi untuk membantuk wacana yang utuh. Faktor lain yang juga dapat mempengaruhi kohesifitas, seperti pengetahuan budaya yang juga membantu dalam menciptakan koherensi teks. 
Konteks memiliki peranan yang penting untuk menafsirkan makna yang terkandung baik dalam wacana lisan maupun wacana tulisan. Mey (2001: 39) pun berpendapat bahwa konteks merupakan konsep yang dinamis dan bukan konsep yang statis. Konteks wacana dibentuk oleh berbagai unsur, yaitu situasi, pembicara, pendengar, waktu, tempat, adegan, topik, peristiwa, bentuk amanat, kode, saluran (Hasan Alwi 1998:421). Konteks wacana meliputi:

a. Konteks fisik (physical context) yang meliputi tempat terjadinya pemakaian bahasa pada suatu komunitas, objek yang disajikan dalam peristiwa komunikasi itu dan tindakan atau perilaku dari pada peran dalam peristiwa komunikasi itu.

b. Konteks epistemis (epistemic context) atau latar belakang pengetahuan yang sama-sama diketahui oleh para pembicara maupun pendengar.

c. Konteks linguistik (linguistic context) yang terdiri atas kalimat-kalimat atau tuturan-tuturan yang mendahului satu kalimat atau tuturan tertentu dalam peristiwa komunikasi.

d. Konteks sosial (social context) yaitu relasi sosial dan latar setting yang melengkapi hubungan antara pembicara (penutur) dengan pendengar (mitra tutur).

Dalam contoh kasus iklan Harbolnas BukaLapak.com versi sakit jiwa 1 dan versi sakit jiwa 2, bahasa iklan yang digunakan merupakan bahasa sehari-hari dalam percakapan tindak tutur nonbaku atau ragam gaul dalam percakapan antar penutur dengan usia sebanding dan menggunakan bentuk kalimat tidak lengkap dan ragam tak baku yang berbaur, bercampur kode dengan bahasa pergaulan sehari-hari dalam dialog tekstual iklan.

BukaLapak.com dalam iklan Harbolnas versi sakit Jiwa mempergunakan ikon tokoh musisi Indonesia, berkepala botak dalam tayangan iklannya. Pada versi lainnya menggunakan tokoh wanita dengan gaya masa kini yang sedang sibuk berfoto diri atau dikenal dengan istilah selfie. Iklan tersebut menonjolkan sisi konsumtif dari manusia dan juga menonjolkan realita sosial bahwa manusia akan semakin mengaggumi dirinya sendiri atau self-centered oriented. 
Penulis menganggap ada realitas sosial yang sengaja dibentuk untuk mempengaruhi khalayak sasaran, dari penggunaan visual tersebut dan juga penggunaan teks dalam iklan tersebut. Hal ini dikarenakan, dalam melakukan promosinya terkait Hari Belanja Nasional di tahun 2016 atau HARBOLNAS 2016, BukaLapak.com menggunakan kata-kata yang singkat, jelas dan mendorong orang untuk segera berbuat sesuatu dalam hal berbelanja. BukaLapak.com ingin mengubah pola pikir khalayak sasaran untuk selalu konsumtif dalam hal berbelanja dengan memanfaatkan momen-momen promosi, semisal potongan harga besar-besaran.

Realitas yang ditampilkan dalam iklan, bukanlah sebuah sebuah cermin realitas sosial yang jujur. Tapi iklan adalah sebuah cermin yang cenderung mendistorsi realitas, atau Marchand (1985) dalam Morris (2003: 169) menyebutnya sebagai a hall of distorting mirrors. Iklan cenderung membangun realitas yang cemerlang, melebih-lebihkan, dan melakukan seleksi tandatanda atau images, sehingga tidak merefleksikan realitas akan kebenaran tetapi mengatakan sesuatu tentang realitas semu. Sejalan dengan pendapat Morris (2003: 170) iklan merangkum dilema-dilema sosial atau aspek-aspek realitas sosial dan mempresentasikannya secara tidak jujur. Iklan menjadi cermin yang mendistorsi realitas yang dipresentasikannya dan sekaligus menampilkan images dalam visinya (Morris, 2003: 170).

\section{KESIMPULAN}

Dengan adanya analisa wacana iklan HARBOLNAS BukaLapak.com versi sakit jiwa dengan menggunakan kajian kohesi dan kontekstual dari beberapa versi iklannya, penulis mendapatkan analisis gramatikal, kohesinya dari versi iklan tersebut. Dalam unsur gramatikal terdapat, kata-kata atau kelompok kata yang menjadi referensi, subtitusi, dan ellipsis. Dimana kesemuanya berkaitan antara satu dengan yang lain, sehingga bisa dikatakan iklan tersebut kohesif. Dengan adanya contoh analisis iklan yang penulis jelaskan dari iklan tersebut dalam makalah ini, dapat disimpulkan bahwa iklan HARBOLNAS BukaLapak.com versi sakit jiwa sesuai dengan wacana iklan yang digunakan demi menarik perhatian konsumen serta memengaruhinya.

Pelibat dalam wacana iklan tersebut meliputi pengiklan dan pembaca iklan. Pengiklan tersirat dalam bentuk merek dagang, gambar media cetak, slogan yang digunakan, dan alamat pengiklan. Pembaca dapat diidentifikasikan berdasarkan penggunaan gaya bahasa dalam kalimat 
didalam iklan tersebut. Wacana bahasa iklan tersebut sengaja digunakan walaupun tidak sesuai dengan kaidah bahasa, lebih karena upaya dari pihak pengiklan kepada pembaca untuk memberikan informasi secara singkat dan dengan dampak yang segera dapat mempengaruhi pembaca.

\section{DAFTAR PUSTAKA}

Alwi, Hasan. 1998. Tata Bahasa Baku Bahasa Indonesia Edisi 3. Jakarta: Balai Pustaka.

Darmawan, Ferry. 2005. "Posmodernisme Kode Visual dalam Iklan Komersial”. Jurnal Komunikasi Mediator.

Iriantara, Yosal., 1993. Periklanan: Konsep, Pendekatan, dan Praktik. Jakarta: Simbiosa Rekatama.

Keraf, Gorys., 1985. Komposisi. Manggarai: Penerbit Nusa Indah.

Mey, Jacob L. 2001. Pragmatics: An Introduction. Australia: Blackwell Publishing.

Mulyana. 2005. Kajian Wacana Teori, Metode, dan Aplikasi Prinsip-Prinsip Analisis Wacana. Yogyakarta: Tiara Wacana.

Morris, John L., 2003. Textual Analysis in Journalism, New York: McGraw-Hill

Noviani, Ratna. 2002. “Jalan Tengah Memahami Iklan” dalam Analisis Wacana: Iklan, Lagu, Puisi, Cerpen, Novel, Drama. Bandung: Pakar Raya.

Rani, Abdul., Bustanul Arifin, dan Martutik. 2006. Analisis Wacana Sebuah Kajian Bahasa dalam Pemakaian. Malang: Bayumedia Publishing.

Sudaryat, Yayat. 2008. Makna dalam Wacana. Bandung: Yrama Widya. 
Sugiyono. 2012. Metode Penelitian Kuantitatif, Kualitatif dan R\&D. Bandung.: Alfabeta.

Sumarlam, Anik Kusrianti, et.al., 2004. Analisis Wacana: Iklan, Lagu, Puisi, Cerpen, Novel, Drama. Bandung: Pakar Raya.

\section{Sumber lain:}

https://www.bukalapak.com/about diakses pada tanggal 6 Desember 2016.

$\mathbf{1 6}$ |Communicology Vol 6 No.2 Des. 2018 